\title{
International Survey on the Management of Esophageal Atresia
}

\author{
Augusto Zani ${ }^{1,2}$ Simon Eaton ${ }^{1}$ Michael E. Hoellwarth ${ }^{3}$ Prem Puri ${ }^{4}$ Juan Tovar ${ }^{5}$ Guenter Fasching ${ }^{6}$ \\ Pietro Bagolan ${ }^{7}$ Marija Lukac ${ }^{8}$ Rene Wijnen ${ }^{9}$ Joachim F. Kuebler ${ }^{10}$ Giovanni Cecchetto ${ }^{11}$ \\ Risto Rintala ${ }^{12}$ Agostino Pierro ${ }^{1,13}$
}

${ }^{1}$ Department of Pediatric Surgery, University College London Institute of Child Health, London, United Kingdom

2 Department of Pediatric Surgery, Sapienza University of Rome, Rome, Italy

${ }^{3}$ Department of Pediatric and Adolescents Surgery, Medical University of Graz, Graz, Austria

${ }^{4}$ Department of Pediatric Surgery, National Children's Research Centre, Dublin, Ireland

${ }^{5}$ Department of Pediatric Surgery, Hospital Universitario La Paz, Madrid, Spain

${ }^{6}$ Department of Pediatric Surgery, Klagenfurt General Hospital, Klagenfurt, Austria

${ }^{7}$ Neonatal Surgery Unit, Bambino Gesù Children's Research Hospital, Rome, Italy

${ }^{8}$ Department of Pediatric Surgery, Faculty of Medicine, University Children's Hospital, Belgrade, Serbia

${ }^{9}$ Department of Pediatric Surgery, Erasmus MC, Sophia in Erasmus MC Sophia Childrens' Hospital, Rotterdam, The Netherlands

10 Department of Pediatric Surgery, Hannover Medical School, Hannover, Niedersachsen, Germany

${ }^{11}$ Department of Pediatric Surgery, University Hospital of Padua, Padova, Italy

12 Department of Pediatric Surgery, Hospital for Children and Adolescents, Helsinki, Finland

13 Division of General and Thoracic Surgery, The Hospital for Sick Children, Toronto, Canada

Eur J Pediatr Surg 2014;24:3-8.
Address for correspondence Agostino Pierro, MD, Division of General And Thoracic Surgery, Hospital for Sick Children, Toronto, Canada (e-mail: agostino.pierro@sickkids.ca).
Abstract
Keywords
- esophageal atresia
- thoracoscopy
- pure esophageal atresia
- esophageal replacement
- Europe

Introduction Because many aspects of the management of esophageal atresia (EA) are still controversial, we evaluated the practice patterns of this condition across Europe.

Methods A survey was completed by 178 delegates (from 45 [27 European] countries; 88\% senior respondents) at the EUPSA-BAPS 2012.

Results Approximately $66 \%$ of respondents work in centers where more than five EA repairs are performed per year. Preoperatively, $81 \%$ of respondents request an echocardiogram, and only $43 \%$ of respondents routinely perform preoperative bronchoscopy. Approximately $94 \%$ of respondents prefer an open approach, which is extrapleural in $71 \%$ of respondents. There were no differences in use of thoracoscopy between Europeans (10\%) and non-Europeans (11\%, $p=$ nonsignificant). Approximately $60 \%$ of respondents measure the gap intraoperatively. A transanastomotic tube $(90 \%)$ received

May 15, 2013

accepted

June 9, 2013

published online

August 9, 2013 (c) 2014 Georg Thieme Verlag KG

Stuttgart · New York
DOI http://dx.doi.org/ 10.1055/s-0033-1350058. ISSN 0939-7248. 
and chest drain (69\%) are left in situ. Elective paralysis is adopted by $56 \%$ of respondents mainly for anastomosis tension (65\%). About $72 \%$ of respondents routinely request a contrast study on postoperative day 7 (2-14). Approximately $54 \%$ of respondents use parenteral nutrition, $40 \%$ of respondents start transanastomotic feeds on postoperative day 1 , and $89 \%$ of respondents start oral feeds after postoperative day 5 . Pure EA: $46 \%$ of respondents work in centers that repair two or more than two pure EA a year. About $60 \%$ of respondents opt for delayed primary anastomosis at 3 months (1-12 months) with gastrostomy formation without esophagostomy. Anastomosis is achieved with open approach by $85 \%$ of respondents. About $47 \%$ of respondents attempt elongation of esophageal ends via Foker technique (43\%) or with serial dilations with bougies (41\%). Approximately $67 \%$ of respondents always attempt an anastomosis. Gastric interposition is the commonest esophageal substitution.

Conclusion Many aspects of EA management are lacking consensus. Minimally invasive repair is still sporadic. We recommend establishment of an EA registry.

\section{Introduction}

Esophageal atresia (EA) with or without tracheoesophageal fistula (TEF) has always been considered as an index pediatric surgical condition, as the result of its treatment have often been used to portrait the standards of care provided by different institutions. ${ }^{1}$ However, in spite of the advances in neonatal care, anesthesia, and technologies many aspects of the management of this condition still remain controversial.

The aim of this study was to identify practice patterns in the management of EA-TEF and pure EA, and to ascertain the degree of variability among pediatric surgical centers.

\section{Methods}

A questionnaire was administered to delegates attending the EUPSA-BAPS Joint Congress (Rome, June 13-16, 2012) and it was collected on the last day of the conference. Respondents were asked to fill in their position (Head of Department/ Permanent Staff or Consultant/Trainee), hospital, and country of practice. The questionnaire was divided into the following two parts: (1) questions on the pre-, intra-, and postoperative management of EA-TEF ( - Fig. 1A); and (2) questions on controversial aspects of pure EA management ( - Fig. 1B).

Questionnaires were completed by 178 delegates, including 38 heads of department, 107 consultants, and 18 trainees. Of the 178 delegates, 15 did not disclose their degree.

On the 168 questionnaires, respondents reported their country of origin. A total of 131 were from 27 European countries (78\%) and 37 were from 18 non-European countries (22\%).

\section{Results}

\section{Esophageal Atresia with Trachea-Esophageal Fistula}

\section{Center}

Overall, 54 (31\%) respondents work in centers that treat 2 to 5 EA-TEF a year, 64 (36\%) respondents reported working in a center that treats 5 to 10 EA-TEF a year, and 52 (30\%) respondents in a center that treats more than 10 EA-TEF a year. Only 6 (3\%) respondents work in a center that treats less than 2 EA-TEF a year. A total of 119 (67\%) respondents work in centers where there are only selected respondents (median, 3; range, 1-10) who operate on EA-TEF.

\section{Preoperative Evaluation}

The majority of respondents ( $n=143 ; 81 \%$ ) would request a preoperative echocardiogram. However, in case of a rightsided aortic arch, only 56\% $(n=96)$ of respondents would opt for a left thoracotomy. The majority of respondents $(n=99$; $56 \%$ ) do not routinely perform a preoperative endoscopy, whereas $43 \%$ of respondents perform a preoperative bronchoscopy either isolated $(n=57 ; 32 \%)$ or in combination with an esophagoscopy ( $n=20 ; 11 \%)$.

\section{Surgery}

The preferred surgical approach for EA-TEF is open thoracotomy ( $n=160$; 94\%), with thoracoscopy favored by a minority ( $n=10 ; 6 \%)$. Most respondents would access the esophagus extrapleurally ( $n=114$; $71 \%$ ); some would perform musclesparing ( $n=70 ; 44 \%$ ), and some would open the chest posterolaterally ( $n=90 ; 56 \%)$. The axillary approach is performed by $24 \%$ ( $n=38$ ) of respondents.

\section{Gap Assessment, Transanastomotic Tubes, and Chest Drains}

Approximately $60 \%$ ( $n=99$ ) of respondents routinely measure the gap intraoperatively, either before $(n=49 ; 52 \%)$ or after $(n=30 ; 32 \%)$ or both before and after $(n=15 ; 16 \%)$ the surgical repair. The majority leave a transanastomotic tube in situ $(n=160 ; 90 \%)$ and routinely insert a chest drain $(n=122 ; 69 \%)$.

\section{Postoperative Care and Feeding}

Postoperative elective paralysis is adopted by $56 \%$ ( $n=99$ ) of respondents. Patients are maintained paralyzed for a median of 2 days (range, 1-7), to avoid tension on the esophageal 


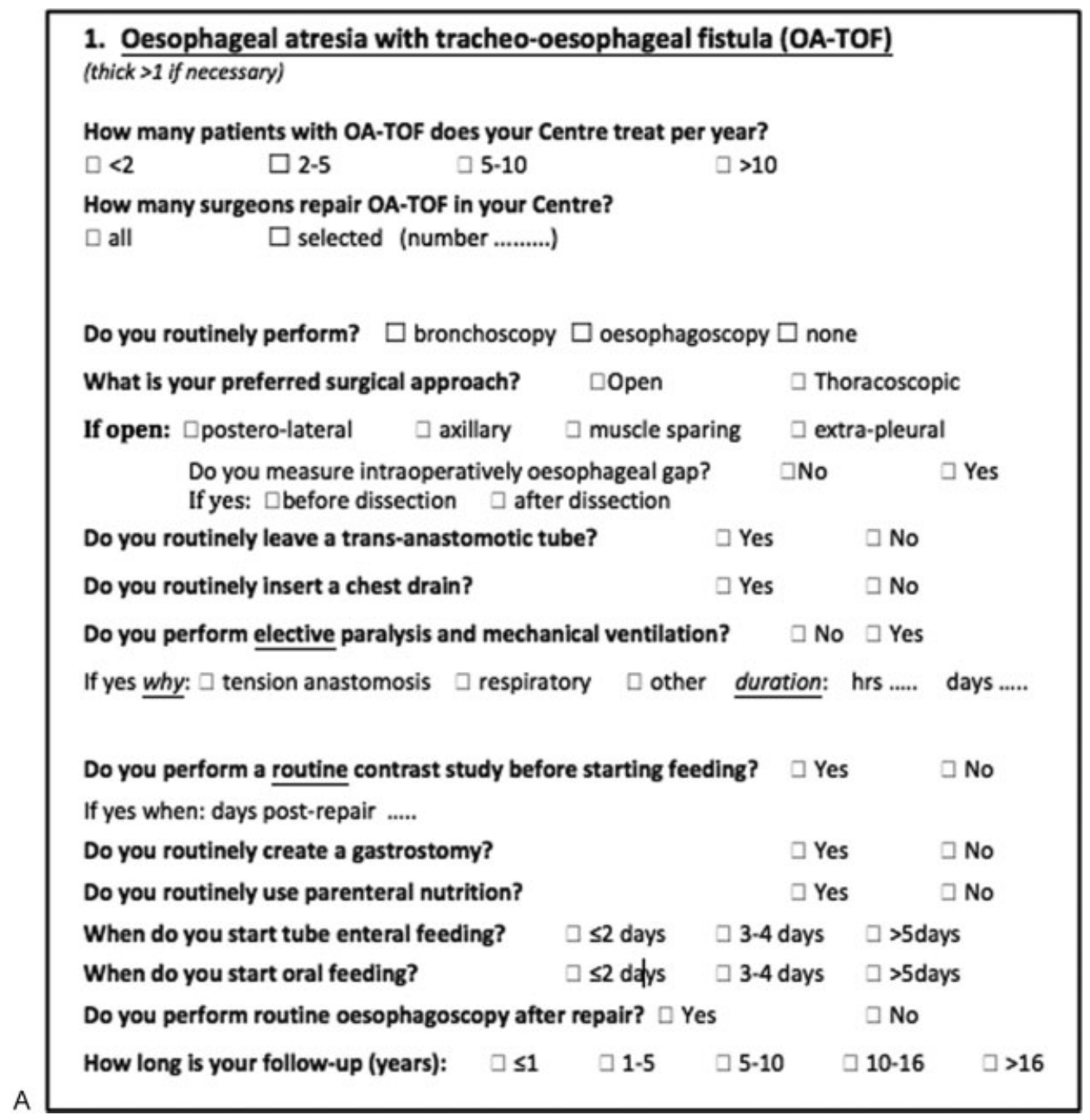

Fig. 1 The questionnaire administered to the delegates of the 2012 EUPSA-BAPS Joint Congress: (A) esophageal atresia (EA) and tracheaesophageal fistula (TEF); (B) pure EA (without) TEF.

anastomosis ( $n=57,63 \%$ ), for respiratory concerns ( $n=15$; $17 \%)$ or for both $(n=18,20 \%)$.

Before starting feeding, $72 \%(n=127)$ of respondents perform a routine contrast study at a median of 7 (range, $2-14)$ postoperative days. Only $2 \%(n=4)$ of respondents create a gastrostomy at the time of EA-TEF repair. Parenteral nutrition is routinely used by $54 \%(n=94)$ of respondents. Enteral feeding via the transanastomotic tube is started on or before postoperative day 2 by $40 \%(n=69)$ of respondents, on postoperative day 3 or day 4 by $35 \%(n=60)$ of respondents and on day 5 or after that by $25 \%(n=43)$ of respondents. Oral feeding is started on postoperative day 3 or day 4 by only $11 \%$ ( $n=19$ ) of respondents, with the vast majority instead after postoperative day 5 ( $n=156,89 \%)$. The general trend is not to perform esophagoscopy routinely ( $n=144,81 \%$ ). Postoperative follow-up of EA-TEF patients is variable: less than 1 year by $2 \%(n=4)$ of respondents, between 1 and 5 years by $27 \%(n=48)$ of respondents, between 5 and 10 years by $24 \%$ $(n=43)$ of respondents, between 10 and 16 years by $26 \%$ $(n=45)$ of respondents, and beyond 16 years of age by $21 \%$ $(n=37)$ of respondents.

\section{Pure Esophageal Atresia}

Only 80 (45\%) questionnaires contained accurate data on this section of the study.

\section{Center}

About $54 \%(n=43)$ of respondents work in a center that treat less than 1 case of pure EA a year, 37\% $(n=29)$ of respondents treat between 2 and 4 cases a year, and only 9\% $(n=7)$ of respondents treat more than 4 cases a year.

\section{Surgical Management}

The most popular preferred management for pure EA is delayed primary anastomosis with gastrostomy formation without esophagostomy ( $n=48,60 \%$ ), followed by attempted primary anastomosis with no esophagostomy or gastrostomy ( $n=19,24 \%$ ), and delayed primary anastomosis with esophagostomy and gastrostomy formation $(n=13$, $16 \%$ ). A delayed anastomosis is usually performed at a median of 3 months (range, 1-12). Most respondents measure the gap using vertebral bodies alone or measuring the distance in centimeters ( $n=67,86 \%)$. 


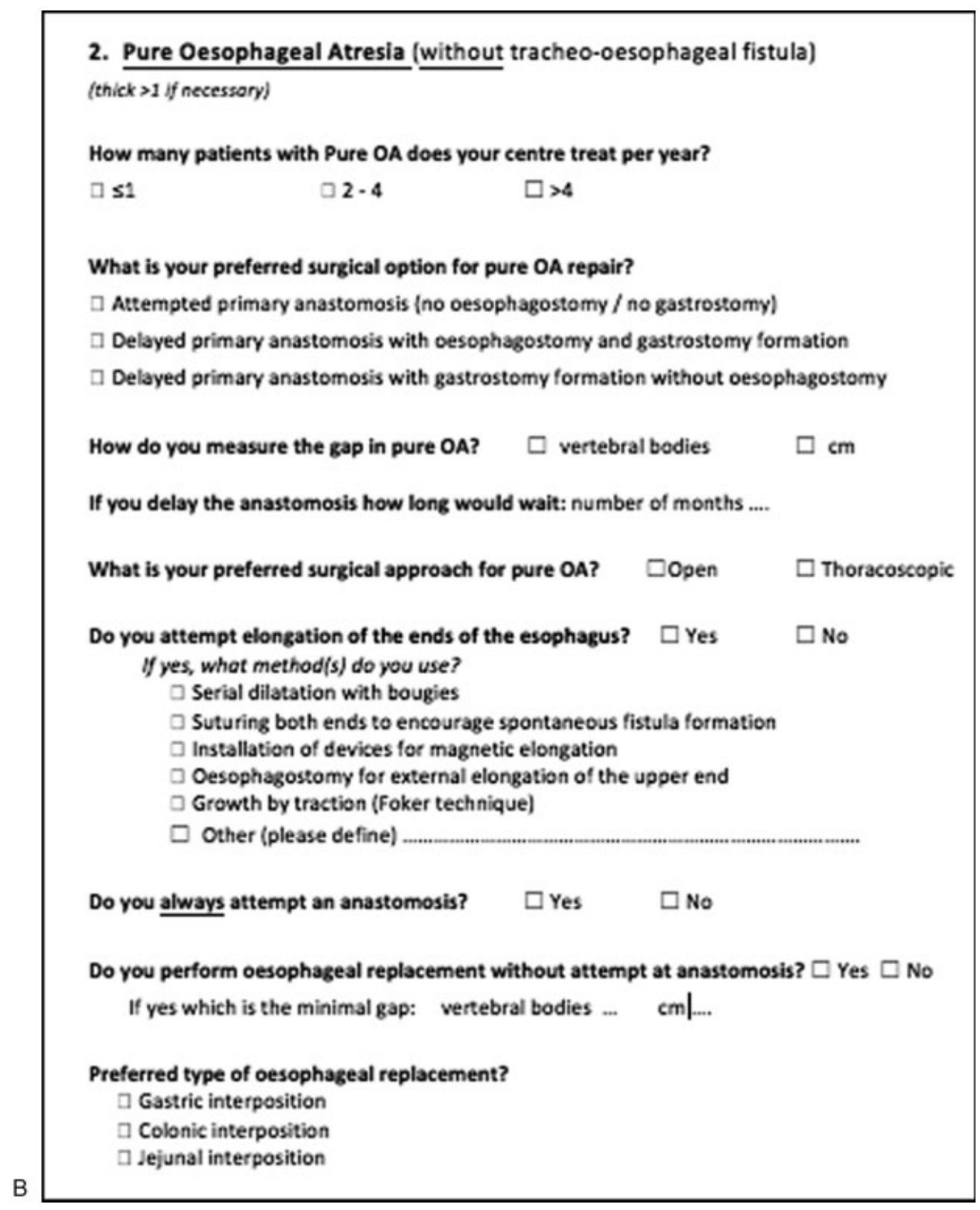

Fig. 1 (Continued)

The favored surgical approach is open surgery ( $n=68$, $85 \%)$. Elongation of the ends of the esophagus is attempted by $47 \%$ ( $n=37)$ of respondents, mainly via growth by traction (Foker technique, $n=16,43 \%)^{2}$ and serial dilatation with bouginage ( $n=15,41 \%$ ). A minority would suture both ends to encourage spontaneous fistula formation $(n=3,8 \%)$, fashion an esophagostomy for external elongation of the upper end ( $n=2,5 \%$ ) or perform a circular myotomy of the proximal esophagus $(n=1,3 \%)$. Approximately $67 \%(n=51)$ of respondents always attempt an esophageal anastomosis. Approximately $23 \%(n=16)$ of respondents perform esophageal replacement without attempt at anastomosis when the median gap is at least $5 \mathrm{~cm}$ (range, 4-7) or four vertebral bodies.
Esophageal Replacement

The preferred type of esophageal replacement is gastric interposition ( $n=36,51 \%)$, followed by colonic $(n=25$, $36 \%)$, jejunal ( $n=6,9 \%)$, and gastric tube $(n=3,4 \%)$.

\section{Discussion}

Many aspects of the management of EA, especially in its pure form, are still lacking consensus.

Because of the rarity of the disease and the specialized assistance that it requires, once the diagnosis has been established, the infant with EA should be transferred from the birthplace to a regional pediatric surgical center. ${ }^{3}$ In an era of service centralization and superspecialization, our 
survey reveals a trend toward selecting respondents dedicated to EA-TEF surgery, as evidenced by two-thirds of the respondents. This is in line with the recommendations by Spitz "[...] to improve OA outcome, centralisation and concentration of patients are advocated particularly in case of pure OA, replacement procedures, recurrent TOF, severe tracheomalacia, and associated major cardiac defects."

Preoperative echocardiography is favored by the vast majority of respondents. This is in agreement with the UK National multicenter cohort study, where echocardiography before surgery was done in $83 \%$ of patients. ${ }^{5}$ However, echocardiography has been reported to correctly identify a right-sided aortic arch in only a proportion of patients. 6,7 Conventional imaging in such patients is often inaccurate and leads to a thoracotomy on the same side of the aortic arch., Nonetheless, half of the respondents in our survey would opt for a left thoracotomy in case of a right-sided aortic arch. In this light, echocardiography seems to be requested more to answer preoperative anesthetic questions than to drive the surgical approach.

Although supported by some authors, ${ }^{8,9}$ the use of perioperative endoscopy still remains controversial. Our survey shows that nearly half of the respondents perform preoperative endoscopy, mainly bronchoscopy. This confirms that some respondents consider it an important procedure to detect an upper pouch fistula, whereas others do not rely on this investigation.

Although thoracoscopic repair of EA-TEF has been described more than 10 years ago, this approach is performed at only a few centers. A recent meta-analysis has confirmed the effectiveness of this approach, which seems to have outcomes not different from those of open surgery. ${ }^{10}$ However, the skepticism toward thoracoscopy could be explained by the difficulty of the technique, associated with a steep learning curve for a rare condition, by the lack of randomized controlled trials that evidence its efficacy, and by the unknown effects that this approach might have on patient metabolism. Recently, in a pilot randomized controlled trial, Bishay et al reported a trend toward worse acidosis and hypercapnia in thoracoscopic EA/TEF repair compared with open repair. ${ }^{11}$ The European skepticism highlighted by our survey is confirmed by the UK/ Irish experience, where only 3 of 120 neonates (2.5\%) underwent a successful thoracoscopic approach. ${ }^{5}$

For EA-TEF open repair, respondents have different approaches. The axillary incision proposed by Bianchi et $\mathrm{al}^{12}$ is adopted by only one-fourth of the respondents.

A transanastomotic tube is left in situ by the vast majority of respondents (90\%), which is in agreement with the reported $100 \%$ use in primarily repaired neonates in the United Kingdom. ${ }^{5}$ Chest drains are electively inserted by a remarkable number of respondents (69\%), and this parallels again the UK practice, where drains were placed at the time of repair in $54 \%$ of procedures, ${ }^{5}$ although this issue has been debated. ${ }^{13-16}$

More than half of the respondents electively paralyze their patients, mainly to reduce anastomotic complications by decreasing anastomotic tension. This approach, initially described by Spitz et al in $1987,{ }^{17}$ later reported by some groups, ${ }^{18,19}$ should decrease the risk of anastomotic complications.

A contrast study is routinely requested by more than $70 \%$ of the respondents. This is not routine practice in the United Kingdom, where contrast studies are usually not requested because they rarely detect a leak, delay feeding commencement, and prolong hospital stay. ${ }^{5}$ This practice is on the basis of the fact that an early routine contrast study does not influence clinical management, as minor leaks do not have clinical significance and major leaks are anyhow clinically evident. ${ }^{3,20}$

Postoperative feeding is mainly achieved via the transanastomotic tube, whereas parenteral nutrition is adopted by half of respondents and gastrostomy use is rare. This is in keeping with a Canadian retrospective study, which demonstrated that feeding via a transanastomotic tube might lead to shorter parenteral nutrition duration. ${ }^{21}$

Pure EA is a variant that most respondents manage uncommonly. This form of EA is preferably managed by almost two-thirds of respondents by delayed primary anastomosis with gastrostomy formation without esophagostomy. According to a recent meta-analysis, this approach provides good long-term functional results. ${ }^{22}$ The delayed primary anastomosis is performed by most respondents at 3 months of age, similarly to the 11.9 weeks of the literature. ${ }^{22}$ As for EA-TEF, the favorite surgical approach of the respondents for pure EA is open.

Elongation of the esophageal ends is attempted using the Foker technique by a very similar number of respondents (43\%) to that reported in a previous survey on the management of pure EA (39\%). ${ }^{23}$

When esophageal replacement is needed, the stomach is slightly preferred over colon and jejunum. A recent metaanalysis of esophageal replacement in children failed to show any advantage of one technique over the others. ${ }^{24}$ This study, like others on this subject, highlighted the lack of prospective comparative studies in the literature.

In conclusion, this survey has confirmed that there are still unsolved controversies in the management of EA, for both EA-TEF and pure EA variants.

Given the rarity of the condition and the need for homogenizing various aspects of treatment, we recommend the establishment of an EA registry. This registry would provide an accurate picture of the incidence and outcomes of EA across the participating centers, it would represent an accurate source of data to aid surveillance, and it would be a resource for research, audit, and service planning.

Conflict of Interest

None.

\section{References}

1 Tovar JA, Fragoso AC. Current controversies in the surgical treatment of esophageal atresia. Scand J Surg 2011;100(4):273-278

2 Foker JE, Linden BC, Boyle EM Jr, Marquardt C. Development of a true primary repair for the full spectrum of esophageal atresia. Ann Surg 1997;226(4):533-541, discussion 541-543 
3 Spitz L. Oesophageal atresia. Orphanet J Rare Dis 2007;2:24

4 Spitz L. Oesophageal atresia treatment: a 21st-century perspective. J Pediatr Gastroenterol Nutr 2011;52(Suppl 1):S12

5 Burge DM, Shah K, Spark P, et al; British Association of Paediatric Surgeons Congenital Anomalies Surveillance System (BAPS-CASS). Contemporary management and outcomes for infants born with oesophageal atresia. Br J Surg 2013;100(4):515-521

6 Babu R, Pierro A, Spitz L, Drake DP, Kiely EM. The management of oesophageal atresia in neonates with right-sided aortic arch. J Pediatr Surg 2000;35(1):56-58

7 Allen SR, Ignacio R, Falcone RA, et al. The effect of a right-sided aortic arch on outcome in children with esophageal atresia and tracheoesophageal fistula. J Pediatr Surg 2006;41(3):479-483

8 Atzori P, lacobelli BD, Bottero S, et al. Preoperative tracheobronchoscopy in newborns with esophageal atresia: does it matter? J Pediatr Surg 2006;41(6):1054-1057

9 Shoshany G, Vatzian A, Ilivitzki A, Smolkin T, Hakim F, Makhoul IR. Near-missed upper tracheoesophageal fistula in esophageal atresia. Eur J Pediatr 2009;168(10):1281-1284

10 Borruto FA, Impellizzeri P, Montalto AS, et al. Thoracoscopy versus thoracotomy for esophageal atresia and tracheoesophageal fistula repair: review of the literature and meta-analysis. Eur J Pediatr Surg 2012;22(6):415-419

11 Bishay M, Giacomello L, Retrosi G, et al. Hypercapnia and acidosis during open and thoracoscopic repair of congenital diaphragmatic hernia and esophageal atresia: Results of a pilot randomized controlled trial. Ann Surg 2013

12 Bianchi A, Sowande O, Alizai NK, Rampersad B. Aesthetics and lateral thoracotomy in the neonate. J Pediatr Surg 1998;33(12): 1798-1800

13 Aslanabadi S, Jamshidi M, Tubbs RS, Shoja MM. The role of prophylactic chest drainage in the operative management of esophageal atresia with tracheoesophageal fistula. Pediatr Surg Int 2009;25(4):365-368
14 Spitz L. Esophageal atresia. Lessons I have learned in a 40-year experience. J Pediatr Surg 2006;41(10):1635-1640

15 McCallion WA, Hannon RJ, Boston VE. Prophylactic extrapleural chest drainage following repair of esophageal atresia: is it necessary? J Pediatr Surg 1992;27(5):561

16 Kay S, Shaw K. Revisiting the role of routine retropleural drainage after repair of esophageal atresia with distal tracheoesophageal fistula. J Pediatr Surg 1999;34(7):1082-1085

17 Spitz L, Kiely E, Brereton RJ. Esophageal atresia: five year experience with 148 cases. J Pediatr Surg 1987;22(2):103-108

18 Al-Salem AH, Qaisaruddin S, Srair HA, Dabbous IA, Al-Hayek R. Elective, postoperative ventilation in the management of esophageal atresia and tracheoesophageal fistula. Pediatr Surg Int 1997; 12(4):261-263

19 Uchida K, Inoue M, Otake K, et al. Efficacy of postoperative elective ventilatory support for leakage protection in primary anastomosis of congenital esophageal atresia. Pediatr Surg Int 2006;22(6):496-499

20 Nambirajan L, Rintala RJ, Losty PD, Carty H, Lloyd DA. The value of early postoperative oesophagography following repair of oesophageal atresia. Pediatr Surg Int 1998;13(2-3):76-78

21 Alabbad SI, Ryckman J, Puligandla PS, Shaw K, Nguyen LT, Laberge JM. Use of transanastomotic feeding tubes during esophageal atresia repair. J Pediatr Surg 2009;44(5):902-905

22 Friedmacher F, Puri P. Delayed primary anastomosis for management of long-gap esophageal atresia: a meta-analysis of complications and long-term outcome. Pediatr Surg Int 2012;28(9): 899-906

23 Ron O, De Coppi P, Pierro A. The surgical approach to esophageal atresia repair and the management of long-gap atresia: results of a survey. Semin Pediatr Surg 2009;18(1):44-49

24 Gallo G, Zwaveling S, Groen H, Van der Zee D, Hulscher J. Long-gap esophageal atresia: a meta-analysis of jejunal interposition, colon interposition, and gastric pull-up. Eur J Pediatr Surg 2012;22(6): $420-425$ 